\title{
Dibujo infantil y comprensión escénica: análisis crítico hermenéutico desde un enfoque psicoanalítico
}

\author{
Jorge Sanabria León \\ Escuela de Psicología, Universidad de Costa Rica \\ Dirección postal: Posgrado en Psicología, Apartado 11501-2060, Universidad de Costa Rica \\ Ce: jorgeserious@gmail.com
}

Resumen. El artículo indaga sobre el desarrollo de la capacidad para dibujar y las representaciones simbólicas prelingüísticas ante el advenimiento del lenguaje. Se examina cómo los y las infantes logran dibujar y hablar sobre experiencias de la vida cotidiana, al focalizarse en detalles de los modelos interactivos en sus propias creaciones espontáneas. A partir de la teoría de la socialización y del desarrollo del símbolo de Lorenzer, este estudio reflexiona sobre la comprensión escénica que favorece la labor analítica. Asimismo, una combinación particularmente importante de habilidades emocionales, cognitivas y simbólicas está involucrada tanto en los procesos de la individuación como en la adquisición de referentes culturales. Por tanto, el análisis contrasta también investigaciones y críticas comparativas

Palabras clave: dibujos infantiles, desarrollo simbólico, comprensión escénica, socialización temprana.

Abstract. This article asks what happens to young children's developing drawing capacity and the depiction of pre linguistic symbolic performances against a backdrop of dawning language. Examined here is how infants reach drawing and talking capabilities to depict everyday life experiences by focusing on details of interactive models in their own spontaneous creations. Aiming at Lorenzer's theory of socialization and symbol development, this paper reflects on the concept of scenic comprehension that enables the analytical work. A particularly important combination of emotional, cognitive and symbolic skills is also involved in refined complex processes of both individualization and acquisition of cultural background. The analysis is based thus on a framework of comparative research and critiques

Key Words: Children's drawing, symbolic development, scenic comprehension, early socialization 


\section{Introducción}

El dibujo infantil, de inicio espontáneo, muestra procesos de niños y niñas durante la inscripción progresiva a su entorno social (Sanabria, 2010). Toda interacción humana tiene un correlato psico - fisiológico que instaura y refleja las capacidades en cada dominio de la cotidianidad. Esta estructura primordial se constituye desde los albores del individuo, incluso desde los mensajes intrauterinos, en el intercambio entre estímulos filtrados por la madre y las respuestas del embrión (Karmiloff y Karmiloff-Smith, 2001). Sin embargo, estos signos primigenios no podrían descifrarse al interior de códigos de comunicación sin la elaboración simbólica, desde antes del advenimiento del lenguaje articulado, pues la simbolización se encarga de organizar las interacciones a partir de significaciones, al inscribir la experiencia concreta en la memoria y en la fantasía. Niños y niñas irán progresivamente recreando una forma de interacción relativamente pasiva (directa con la madre), por una más proactiva (re-escenificación de situaciones y juego con objetos); la segunda devela el significado de la primera, siempre fundada en interacciones concretas con su entorno, e inaugura la individuación. Cognición, afecto y destrezas se entretejen para colaborar con una simbología presentativa, incluso bajo el posterior dominio del lenguaje, y así permanecer como organización esencial, cercana a la sensibilidad, al inconsciente. Esta colaboración demuestra la posición central de Lorenzer sobre los procesos precursores de la capacidad simbólica. La exposición siguiente mostrará cómo estos tres niveles cooperan durante la producción gráfica para facultar al sujeto la elaboración de un esquema sobre escenas vividas o imaginadas que se desprenden de su historia de socialización, lo que equivale a que muestran su devenir como sujeto social.

\section{Dibujo, socialización, símbolo}

Lorenzer (1986) plantea que en la socialización temprana la interacción con objetos es una forma de apropiación cultural, al manipularlos para incorporar sus atributos. Gracias al objeto, el infante se interna en la praxis colectiva, sin mediación adulta, como vivencia en el juego interactivo en los contextos de vida. Este mundo lúdico abarca vestimenta, enseres y espacios domésticos, arquitectura, entorno urbano y natural, configurados por el ser humano. La individuación resultante sustrae al infante del dominio de la díada, al involucrarle en la colectividad, antes del advenimiento del lenguaje y en alternancia con las figuras lingüísticas, al contactar significados colectivos. Los objetos son vehículos de significado bajo acuerdo colectivo, que se ponen a disposición del infante dentro de una modalidad inmediata y sensorial. Esta proximidad ofrece apertura a la confrontación entre el entorno y el individuo. Asimismo, ciertos objetos transportan un significado libre de propósito, como 
en el concepto de "arte", e independientes del uso instrumental, constituyendo bosquejos sociales de comportamiento. Estos símbolos se diferencian de los del lenguaje al estar integrados a la interacción sensorial inmediata, conformando el área de símbolos presentativos derivados, en correspondencia con el intercambio con el mundo exterior y en contraste con los símbolos lingüísticos, correspondientes a los signos exteriores del lenguaje. Previo al advenimiento del lenguaje, emerge entonces un andamiaje de sentidos (de figuras de la praxis) que conserva formas de socialización culturalmente mediadas. Por tanto, las representaciones plásticas, de las cuales los objetos son tributarios, están más próximas a las emociones que las figuras del lenguaje y sus significados se anclan en un nivel más profundo de la personalidad.

Este juego conduce al establecimiento de una figura de la vivencia en representación de otra, como disponibilidad lúdica sobre las situaciones. Las imágenes presentativas subyacen a fantasías poetizadas y escénicas, a partir de las cuales las figuras del lenguaje incorporan el guión emergente desde las vivencias escénicas y sensoriales, instaurado a partir de procesos corporales fundadores del nivel básico de la subjetividad. En la obra de arte se debaten hábitos y prácticas, desde el panorama artístico (como en el caso del dibujo), que ofrecen a las figuras infantiles, al igual que los objetos, nexos entre significados colectivos y la vivencia individual, fórmulas para la interpretación del mundo y el comportamiento social, figuras del juego social o bosquejos de la interactividad humana con el mundo. Este intercambio se da en la red de comunicación. Asimismo, el dibujo comparte con la gestualidad, el baile, la danza y la música el enlace con la simbología presentativa desde las formas de interacción simbólico - sensoriales.

El dibujo infantil es, entonces, basándose en esta posición de Lorenzer (2002), la representación de un modelo de la práctica de vida, derivada de la inmediatez sensorial, de la complejidad de la praxis humana, una relación simbolizada entre la infantil dibujante y su entorno de vida, como figura central del mundo infantil en un momento de la individuación. En el simbolismo gráfico, la experiencia infantil se destaca entre la imaginería colectiva como expresión singular de la praxis en la que se encuentra inscrito el sujeto en desarrollo. La cualidad presentativa de este nivel simbólico puede combinar la utilidad con la estética (como en la arquitectura) y expresar el contenido de experiencias que no pueden (o no podrían todavía) ser enunciadas en el lenguaje y que carecen (aún) del consenso lingüístico (como los sueños), mucho más próximas a las emociones y al inconsciente que cualquier figura del lenguaje.

Al dibujar, el o la infante otorga a su grafismo un significado que destaca una situación integral, sin desarticular, al igual que la interacción completa con un objeto en el campo inmediato y sensorial, en contrapunto con los símbolos organizados en el lenguaje. Una interacción inmediata y sensorial es sustituida por otra del mismo carácter. 
En la estructura de la subjetividad, las interacciones simbólico - sensoriales corresponden a la simbología presentativa, las interacciones simbólico lingüísticas a los signos del lenguaje; ambos establecen el intercambio con el mundo exterior, de manera que las primeras se inscriben en el sustrato psicofisiológico como una sucesión de huellas escénicas, mientras que en las segundas la escena adquiere un nombre, una figura del lenguaje; la huella sensorio-motriz se consolidará con una del lenguaje, para posibilitar el doble registro de la acción y patrocinar la conciencia. La consolidación de un sistema de sentidos no lingüístico, de figuras de la praxis, es el sustrato para la acción regida por la conciencia.

La disponibilidad lúdica sobre las situaciones excede las fronteras de la discursividad o la presentatividad simbólica, pues evoca imágenes, recuerdos poetizados en la pinacoteca de la fantasía, que muestra cómo incluso a las figuras del lenguaje subyacen sedimentos de las vivencias en forma sensorial escénica; las formas de interacción simbólico-sensoriales empiezan a estructurar la subjetividad, fundamento de la identidad y la autonomía. Individualidad y sociabilidad juegan el intercambio entre vehículos concretos de significados (objetos), simbología presentativa y formas de interacción simbólico sensoriales en la ontogénesis. El dibujo es un gesto individualizado de la praxis en su conjunto, conexión simbólica con el colectivo, en la red de comunicación.

La siguiente exposición rescata los diferentes niveles de subjetivación comprometidos en la producción gráfica y que dan cuenta de los procesos que facultan a la interpretación del dibujo infantil desde la comprensión escénica (Sanabria, 2007). Los diferentes niveles de análisis han de mostrar cómo la individuación (singularización desde la experiencia) es posible por la conjunción de logros en diversas áreas, cada una de las cuales presenta desafíos específicos a el o la novel dibujante.

\section{Destrezas sensorio - motrices}

La estabilidad bimanual en dibujos esféricos basados en coordenadas básicas (Ringenbach y Amazeen, 2005), incrementa su afinamiento intencional en índices de desarrollo de la fuerza de acoplamiento bimanual, coordinación con la intencionalidad del control y relación amplitud-tasa de elaboración (cantidad), en relación con la precisión. Desde la biomecánica, la coordinación bimanual muestra el control conjunto de todas ellas; la maduración proximodistal emplea a menor edad un grupo muscular más grande y proximal, incluso para los movimientos más finos, y conforme avanza el desarrollo se involucran los más distales.

Por su parte, Toomela (2003) intenta determinar la participación de modelos internos durante la ejecución, para establecer cuándo el o la dibujante reproduce un "prototipo" incorporado o está atendiendo, con un "ejemplar", a las características visuales del objeto. El contenido (qué se dibuja) y el sistema de denotación (cómo se dibuja) son dependientes entre sí. Así, propone cuatro 
estadios del dibujo: garabatos o patrones (trazos irreconocibles denotando la presencia de un "algo"); representacional (volumen - prototipo, sistema de denotación, regiones vastas para volúmenes vastos y largas para regiones largas); ejemplares de dos dimensiones (versiones de un modelo, regiones denotando caras del volumen o campos visuales, segmentos representando diferentes caras desde diferentes ángulos, visión y profundidad "irreal", plano frontal-paralelo, no de proyección retinal); consistencia plana al interior y ejemplares tridimensionales (denotados por bordes y contornos, información diferenciada de la proveniente de la forma, realismo visual, ángulo específico de visión en el sistema de proyección y en el contenido). Al contrastar dibujos en edades de $2-$ 14 años y de adultos jóvenes, el autor también demostró el patrón de las etapas mayores apareciendo más tardía y las menores más tempranamente, en un movimiento desde modelos prototípicos internos hacia ejemplares particulares, de los carentes de realismo visual hacia los que lo muestran. Aunque un cubo es más fácil que una muñeca, ambas producciones caen en las mismas categorías, en un sistema progresivo.

Cómo son realizados los dibujos y la variabilidad pictográfica (Braswell y Rosengren, 2000) revelan aspectos que el o la dibujante tiene en su cabeza sobre la exploración de diferentes contextos, así como modos de comportamiento, facilitadores de aprendizaje y adaptación a contextos cambiantes. El dibujar resultaría de la interacción de diversos factores y no de una estrategia fija. Sistemas dinámicos, cronológica e individualmente, identifican a diferentes edades la utilización de distintos estados de atracción, secuencias y modalidades para realizar tareas específicas. Unos son catalogados como de nivel superior o restricciones cognitivas y otros como de nivel inferior o perceptivo - motoras; los segundos tienen que ver con bio-mecanismos de brazo, mano y dedos, los primeros con convencionalismos sociales simbólicos de las figuras y la planificación. Conforme el o la infante gana en experiencia, modos más efectivos facilitan enfrentar restricciones e integrar soluciones, con estados de atracción más estables. El avance significa un conjunto más limitado de comportamientos consolidados con la dinámica del sistema. Como consecuencia de restricciones superiores, susceptibles de influencia social y escolarización (sistemas de escritura y convenciones gráficas aprendidas con otros), aparecen comportamientos consistentes entre individuos y declina la variabilidad.

La memoria M o capacidad de memoria de trabajo (working capacity memory) es destacada por Morra (2005), cuando niños y niñas dibujan una persona que representan de pie y estática, para luego reorganizar esquemas y pasar a una persona recogiendo un objeto y, tercero, una corriendo. Su explicación se basa en: disponibilidad de modelos externos, cambios endógenos en la representación mental y teoría infantil básica e ingenua sobre la representación. Las reconsideraciones para el cambio se encuentran en el segundo, aunque las representaciones tempranas no son rígidas. Asimismo, se subrayan dos 
aspectos: esquemas (representaciones) y recursos de atención; así como dos tipos de esquemas: figurativos y operativos. Los primeros se encargan de representar objetos, conceptos y estados, los segundos asumen acciones, transformaciones y operaciones mentales. Cuando niños y niñas tienen que resolver un problema pictórico e inventan un nuevo esquema, adaptan de otros esquemas figurativos adquiridos previamente con acceso a representaciones visuales o imágenes del objeto, intentando imitarlos. Tres factores intervienen entonces en la habilidad infantil para modificar un dibujo: disponibilidad de modelos, capacidad $\mathrm{M}$ y claridad sobre los requerimientos respecto a una tarea gráfica. El incremento de la habilidad infantil para dibujar y la participación de la capacidad $\mathrm{M}$ en la flexibilidad o flexibilización de esquemas previos y componentes endógenos diferencian a los sujetos, asimismo destacan tres factores: habilidad, en incremento con la edad (coordinar esquemas figurativos y operativos); activación automática de esquemas perceptivos gracias al input perceptivo; y aspectos contextuales (orden y secuencia).

Así, estos estudios resaltan las destrezas sensorio - motrices de niños y niñas, tanto como los patrones que conducen su desarrollo. La cognición acompaña este proceso que tiene sus raíces en la propiocepción, la cual, al derivar en nuevas habilidades, diversifica la capacidad representativa mostrando, como lo plantea Lorenzer (2002), que el dominio sobre la propia imagen corporal, así como los recursos expresivos que proporciona, subyace a las representaciones de las interacciones con objetos y personas en contextos específicos. La madurez sensorio - motriz progresiva es una condición necesaria, pero a su vez se ve beneficiada por el empuje de la producción gráfica, aspecto desatendido en las investigaciones reseñadas.

\section{Procesos de representación}

Las habilidades artísticas en la diversidad de la expresión simbólica y la complementariedad de rigidez y flexibilidad en el dibujo (Boyatzis, 2000) ponen de relieve la "obra de arte" infantil en la comunicación infante - adulto y en la socialización artística, que se presenta en un contexto interpersonal, un contrato entre el infante - artista y un espectador. La observación sobre cómo se dibuja y los comentarios del infante durante la elaboración permiten inferencias sobre instancias microgenéticas, sin la preocupación por estadios o secuencias del desarrollo. El dibujo evoluciona desde la correspondencia símbolo-referente (renacuajo a los dos años y medio, hasta líneas detalladas a los cinco años). El dibujo irá ganando en profundidad y perspectiva, detalles elaborados y formas distinguibles, ilustrando situaciones y actividades con significado. La variabilidad en organización y flexibilidad en las reglas muestra múltiples formas de pensar y dibujar; más que progresión lineal, se trata de una escogencia y diversidad del repertorio disponible, en interacción con el contexto.

Entre los dos a los cinco años de edad, la preeminencia del torso en el dibujo tipo renacuajo (Cox y Mason, 1998) es una representación mental de la 
imagen corporal que muestra cómo la infante dispone de un modelo mental completo y el pictograma es su versión concisa sin priorizar al torso ni la forma de dibujarlo. Las posibles diferencias en el tamaño de figuras masculinas y femeninas de niños y niñas entre cinco y siete años (Cox y Wright, 2000) evidencia que las niñas tienden a dibujar las femeninas más grandes que las masculinas, por medio de detalles que diferencian el género, las cuales también han sido verificadas por Cherney, Seiwert, Dickey y Flichtbeil (2006) y por Tenenbaum, Hill, Joseph y Rochel (2010). Por su parte, Leon, Wallace y Rudy (2007) han indagado este mismo principio, visto además desde el enfoque de las posibles alianzas al interior de la familia.

Los esquemas de género, según Boyatzis y Albertini (2000), se organizan en la temprana niñez, exacerbando la socialización por género en el dibujo. Las diferencias de las experiencias de niños y niñas, debidas a la socialización de normas, influencian el incipiente arte infantil, sintonizándolo con estereotipos societales de género. Esta influencia cultural muestra cómo en las culturas occidentales los motivos se polarizan en determinadas direcciones. Aunque sus hallazgos muestran qué y cómo se dibuja, contrastan con los evidenciados en otras culturas. El grupo de pares se destaca como uno de los más relevantes agentes socializadores, influyente en opiniones, comportamientos, conformidad y adherencia. La influencia de los pares afectaría el aprendizaje basado en la observación, pues el dibujo genera conversaciones que intercambian ideas y comparaciones explícitas, estimulándose cualidades técnicas y significados, en comentarios positivos o negativos que estimulan o disuaden en el intercambio verbal, activador de socio cogniciones, transmisores de influencias en nociones de arte infantil, bajo el realismo y la literalidad, en la "exactitud" de la representación, proveedores de criticismo. La intersubjetividad (la comunicación, y no el habla per se) modela alternativas, verbaliza ideas, soluciones o comprensiones compartidas, proceso que convierte a procesos inter psicológicos en intra psicológicos.

Por su parte, Braswell y Rosengren (2005) refutan la secuencia en el desarrollo del dibujo infantil, por el poco énfasis otorgado a la influencia sociocultural, establecida a través de las culturas y dentro de una misma cultura e históricamente. La variabilidad es indicio de una imaginería mutante según factores sociohistóricos que afectan convenciones y demuestran la relatividad del enfoque endógeno. Abordan la génesis del dibujo desde los esquemas gráficos, que reflejan personalizaciones para algo visto en el mundo o elaborado por el "ojo de la mente", impulsadas por fuerzas endógenas, comprometidas con dispositivos gráficos a adquirir, con rasgos básicos compartidos, durante actividades espontáneas o en clases de arte. Esta habilidad requiere compartir ideales artísticos mediados culturalmente. Importantes serán entonces los mecanismos para adquirirlo. Al producir rasgos básicos, la novel dibujante debe combinar habilidades simbólicas. Primero se producen nuevos esquemas gráficos junto a otros incorporados como repertorio; la provisión de 
información verbal y no verbal de adultos sobre convenciones simbólicas, así como la contribución infantil desde sus aportaciones pictóricas, son dimensiones centrales, desagregadas en léxico, morfología, semántica (conexión léxico - significado), sintaxis (combinación léxico - imágenes más sofisticadas y coherentes) y pragmática o usos simbólicos en el mundo real. Valores y expectativas adultas median la interacción gráfica, como su importancia y su relación con habilidades posteriores (Por ejemplo escritura), así como de la enseñanza del dibujo per se.

Asimismo, los primeros garabatos son exploraciones sobre realidad, forma y movimiento (Merry y Robins, 2001), pues niños y niñas, hasta los cinco años, dibujan desde el "realismo intelectual" (no del "visual"), desde sus cabezas, no de lo observado, porque son "principalmente simbolistas". En esta edad, se pueden modificar patrones básicos al dibujar figuras no existentes (una persona que no puede existir, no puede ser), por medio de "distorsiones" (varias cabezas, muchos dedos) o "reemplazos" (fantasma, payaso), o al solicitar un objeto familiar pero infrecuente en sus dibujos (bicicleta), sucedido por la consigna de dibujar una bicicleta que no existe, no puede ser, con resultados similares, evidencia de cambio, permanencia de estructuras básicas y capacidad para pensar por adelantado y variar patrones; el relato discrimina la capacidad temprana de variar temas. Las variantes preferentes (distorsión o reemplazo) muestran la construcción de soluciones. La importancia del relato asociado también ha sido estudiada por Einarsdottir, Dockett y Perry (2009), a partir del motivo del ingreso a clases escolares, y también por Wu (2009), con resultados similares.

Ahora bien, la descripción interna tridimensional durante la copia de objetos familiares o no familiares ("no objetos") como factor clave de la agudeza del dibujo y su representación lineal (Sheppard, Ropar y Mitchell, 2005), refleja el conocimiento y familiaridad sobre los objetos contribuyentes a su significación y al grafismo, al favorecer combinación y estructuración de los datos disponibles. El significado orienta la atención de detalles a partir de la necesidad o no de su presencia en función de la fidelidad de la producción con respecto al objeto. Este manejo combinado de dimensionalidad y significado se fortalece conforme avanza el desarrollo infantil, destacándose la familiaridad con los objetos. Las propiedades de los objetos, por su descripción tridimensional, dificultan la perspectiva visual que capta solo su apariencia, pues la primera se activa cuando se trata de lograr la segunda, incluso al reproducir objetos inexistentes que sugieren una representación tridimensional. La significación brinda facilitación por el conocimiento disponible y no interferencia; además, favorece el proceso de planificación, al desarticularlo en unidades analizables y con cierta comunidad de rasgos con otras previas y disponibles en la memoria a largo plazo, en integración progresiva, destacándose detalles importantes, identificables en las unidades básicas, que intensifican la atención y se desatenderían en dibujos sobre objetos no familiares. 
Sobre el conocimiento implícito y su manifestación en dibujos, Vinter y Perruchet (2000) apuntan que conforman un modo adaptativo del comportamiento infantil, sensible a características estructurales de cualquier situación experimentada, sin recurrir, deliberadamente, a ningún aspecto del conocimiento explícito sobre el particular, que cubre importantes campos de las adquisiciones perceptivas, cognitivas y motoras, incluyendo aspectos asociados al aprendizaje primario y secundario del lenguaje, conducentes a la elaboración categórica, así como a la lecto-escritura. El proceso inicia con el recién nacido y solo después activará un dispositivo endógeno, responsable del conocimiento explícito, resultante de la redescripción representacional. Este dispositivo favorece la sensibilidad ante estructuras complejas del entorno. Sus representaciones reflejarían adquisición de conocimiento implícito sobre el entorno físico, material y social, estructuras predecesoras del lenguaje.

Panagiotaki, Nobes, y Banerjee (2006) plantean que, dependiendo de los procedimientos para dibujar una temática en particular (por ejemplo, el planeta tierra), así como de las preguntas subsecuentes, niños y niñas desarrollan explicaciones alternativas sobre su producción; la claridad sobre la consigna e intencionalidad de la ejecución es determinante del contenido y las categorías analíticas. La presentación de modelos o la solicitud de hacerlo de memoria, así como preguntas cerradas o abiertas, involucran procesos cognitivos diferenciales y una memoria de trabajo de mayor o menor exigencia. Las preguntas y expectativas de respuestas comprometen la composición gráfica pues median la interpretación infantil sobre el producto esperado, por ejemplo, dibujar la tierra desde la perspectiva en la superficie o desde una visión imaginaria desde el espacio; el supuesto de la perspectiva de una esfera en el espacio, cuando en realidad fue realizada desde alguna otra concepción (plana o circular), genera un error analítico adulto-céntrico y de evaluación de la obra infantil. Preguntas abiertas o de escogencia obligada comprometen combinaciones cognitivas diferenciales, las primeras dejan margen a la interpretación del significado, en las segundas, la preocupación es si se adaptan a la opción escogida.

Por último, Laak, Goede, Aleva y van Rijswijk (2005), con el test del dibujo de una persona, solo han encontrado evidencia para establecer el nivel de desarrollo cognitivo, no así de rasgos de personalidad o de adaptación emocional, la cual coincide con el enfoque de Cox (2005), que pone el énfasis en la intención y el significado.

Como se aprecia, el dibujo es concebido por la infantil dibujante como la representación de dimensiones del sí mismo junto a otros, pues el acto de comunicar por medio del dibujo implica el conocimiento adquirido, la familiaridad personal con los eventos y personajes descritos, así como la intencionalidad del dibujante y la que le atribuye a las personas a quienes potencialmente dirige su obra. La producción misma es decodificada a partir del diálogo que puede establecerse con otros (pares o adultos). Formas de 
interacción simbólico-sensuales (presentativas) derivan desde las experiencias del sujeto hacia el dibujo (simbólico-presentativas) y de ahí hacia la discursividad (el lenguaje), en un juego interactivo como el que favorecen los objetos (Lorenzer, 1986). Los estudios reseñados no cubren esta metacognición que permite al dibujante apelar a un evento externo (persona, objeto o situación) para generar una comunicación triangulada al recrear el contexto en que se lleva a cabo la acción.

Visto de esta manera, el dibujo se constituye en un objeto-recurso para la discursividad en la medida en que sus contenidos son escenas (reales o imaginadas), poetizadas en el dibujo, que solo pueden ser conceptualmente comprensibles al concebir el dibujo como un evento más en su proceso de inscripción en el mundo simbólico resultante (aspecto descuidado en las investigaciones referidas), incluso desde antes del advenimiento del lenguaje y por medio de una producción simbólica de las experiencias individuales vistas desde el ojo interno de la dibujante. Tampoco toma en cuenta la deixis presente en el acto comunicativo que pone de relieve cómo las habilidades sensoriomotrices se activan a partir de la capacidad para ubicar una trama en un contexto.

\section{Dimensiones simbólicas}

Niños y niñas de diferentes culturas se interesan por la expresión de estados de ánimo en sus pictogramas (Jolley, Fenn y Jones, 2004). Por ejemplo, pares de dibujos de un árbol triste y uno alegre establecen propiedades formales de contenidos y cómo se comporta esta combinación de elementos a lo largo del desarrollo; temas y propiedades formales tienden a incrementarse con la edad aunque de una manera variable en cada grupo etario. Una variante de este modelo deja a niños y niñas la elección de los motivos, con la consigna de realizar un dibujo triste, uno alegre y otro enojado, tomando en cuenta la expresión general, la composición, el balance de la presentación y el uso de líneas, como agentes de expresión; así los autores determinan dos momentos del desarrollo pictórico infantil: hacia los cinco años, un patrón progresivo que tiende a disminuir cerca de los 8 y a estabilizarse hacia los 11 - 12 años, con la habilidad estética tendiente a disminuir en lugar de incrementarse. Una extensa medición de los patrones de desarrollo en dibujos infantiles de carácter expresivo, al pedirlos tristes y alegres, tanto como predeterminados, establece el uso de dispositivos para la expresión y calidad general; cuando algunos acentúan el estado de ánimo (calidad) y otros una diversidad de temas de contenido (cuantitativo), el análisis de las combinaciones no va en detrimento de una $\mathrm{u}$ otra modalidad, para identificar diferentes patrones de desarrollo en cuanto a calidad y cantidad, a la vez de contenido y abstracción. El resultado del desarrollo sería la integración de temas expresivos y propiedades formales. La tendencia infantil cada vez más acentuada de dibujar el mundo tal como es, daría énfasis a representaciones realistas y ahogaría la expresividad natural. La 
expresividad se incrementa con la edad, con saltos significativos en indicadores cuantitativos de los 4 a los 9 años y luego a los 12, a partir de la diversidad de temas, aunque sin particularidades en la cantidad de propiedades formales. Este perfil se repite en indicadores cualitativos, con cambios notables entre los 6 y 9 años; patrón seguido en el realismo visual, sugiriendo una relación entre ambos. Las dos habilidades requieren capacidad de representación, pues un dibujo realista puede oponerse a la expresividad; el primero exige un uso preciso de los aspectos formales, la segunda depende de su flexibilidad.

Asimismo, Watson y Schwartz (2000) definen el estilo del grafismo infantil como rasgos distintivos, componentes y cualidades reconocibles por su persistencia en distintas obras del mismo autor. Cada dibujante difiere en elementos distintivos persistentes en la composición, aunque no sean reconocibles siempre para cada individuo. Los jueces fueron capaces de identificar dibujos según sexo del artista, no así de atribuírselos según rangos de edad, salvo en el caso de los preescolares (el rango iba de preescolares hasta tercer grado), cuya predicción tendió a declinar a mayor edad. La distinción estilística se incrementa cuando se incorpora mayor simbolismo en determinados referentes y temas. La influencia de la estandarización, por la atención a estilos de pares y modelos adultos, puede contribuir a la declinación de la singularidad en la producción gráfica; el estilo prevalecerá en quienes se preocupan por desarrollar una representación más estética y creativa. El estilo arroja períodos de incremento y declive, discontinuidades derivadas de intentos por incorporar cambios o de saltos cualitativos en otros dominios.

La utilización del dibujo para registrar influencias de experiencias previas en el comportamiento, recíprocas y permanentes, involucra el conjunto de relaciones sociales del infante (Carlson, Sroufe y Egeland, 2004), determinantes de las expectativas infantiles de la interacción familiar y el orgullo por la pertenencia; el dibujo de la familia evidencia el sentido del infante sobre su "sí mismo" al interior de la familia. El dibujo familiar, clave del modelo longitudinal entre representación y comportamiento, registra expectativas, actitudes y sentimientos respecto a la relación, así como su organización cognitiva y coherencia. Pueden graficarse senderos desde la infancia hasta representaciones no interactivas acumulativas y variables en el adolescente, tanto como influencias entre representación, comportamiento y contribución de cada período.

Como participantes de una red de apego, para Cugmas (2004), el niño y la niña establecen relaciones con figuras alternativas. La variabilidad de la importancia otorgada por el infante a esta diversidad, que incluye a figuras de apego primordiales (por ejemplo madre y padre), tanto como a educadores o cuidadores, es registrable y diferenciable en la producción gráfica. La naturaleza no verbal del dibujo favorece la expresión de emociones y actitudes, de otra manera complejos. Sobre todo en el rango de 5 a 11 años, el dibujo muestra modelos internos de funcionamiento con el sí mismo y el otro, así como la 
relación entrambos. La historia temprana de apego tiene un valor de predicción de la producción gráfica. Al solicitarles a niños y niñas un dibujo titulado "Yo en el jardín infantil" (Myself in the kindergarten), se dibujan a sí mismos, junto con maestros, coetáneos o un juguete, mostrándose constelaciones signadas por rasgos de estilo.

El modelo de Fury, Carlson y Sroufe (1997), que trata la capacidad expresiva y registro en dibujos infantiles sobre modalidades de apego, permite la expresión de emociones, preocupaciones, necesidades, conflictos y actitudes, difíciles de precisar en el rango de 5 a 11 años. Destacan su carácter de comunicación no verbal que recoge sentimientos y pensamiento antes que el infante pueda hacerlo en palabras; las experiencias de apego con el sí mismo, los otros y del sí mismo con los otros ponen de manifiesto modelos internos de funcionamiento. Validar el uso y rasgos muy específicos del dibujo, como representación del apego, de diferentes niveles, incluye signos individuales. Sus resultados destacan la identificación de aspectos subjetivos, personales y posiblemente inconscientes de los modelos de representación del sí mismo (self) y sus relaciones, durante la temprana niñez media, en la cual el juego aún no se ha desarrollado por completo y las habilidades verbales son limitadas.

Burkitt, Barrett y Davis (2003) se preguntan si los dibujos infantiles son un medio confiable para establecer sentimientos de los dibujantes al elaborarlo. Tamaño y colores deberían influenciar tal caracterización. Aparece una diferencia entre la copia de un modelo y el dibujo libre, así como entre afectos relacionados con figuras animadas e inanimadas, con representaciones y relaciones con el mundo real, así como patrones diferenciales por edad de estilos para cualidades requeridas en cada uno. Estas variaciones se referirían a cómo el desarrollo acompaña la adquisición de convenciones para estrategias diversas, aunque sin fases específicas. Que el tamaño sea mayor en los dibujos agradables en relación con los desagradables, pese a poder destacar cualidades por otros medios, pone de relieve este recurso como pivote entre la convención y el mecanismo activado al dibujar; que lo inverso no se haya demostrado pone en duda hallazgos previos sobre dibujos copiados. En cuanto a los colores, se relacionan los preferidos con dibujos agradables y viceversa, con la utilización de colores intermedios para las figuras neutrales, como una aplicación simbólica con una función comunicativa. Esta dinámica variaría cuando los temas son del mundo real infantil sin instrucciones específicas y de preeminencia emotiva.

El dibujo cobra sentido no por sus partes, sino por el conjunto representado, afirman Picard y Vinter (2005), quienes cuestionan la posición sobre sintaxis y semántica del dibujo infantil, como ordenamiento $\mathrm{y}$ organización de movimientos (sintaxis) y contenido en términos simbólicos (semántica), pues no es posible una correspondencia unívoca de estas dimensiones con la forma en que aparecen en el lenguaje. La pregunta sería qué y cómo se representa, en una gramática de la acción. Un dibujo de memoria tiende a mantener consistente el patrón estructurado, aunque no se mantenga la rutina, sino una variabilidad en los trazos. Establecen tres principios básicos: 
acrecentamiento (básico en infantes y adultos para el progreso natural y coherente del dibujo), como la tendencia a dibujar partes subsecuentes sobre las previas; del núcleo a la periferia (de naturaleza más semántica, otorga las partes necesarias para la identificación, diferenciando las esenciales de las accesorias $\mathrm{u}$ ornamentales), como la propensión a iniciar en elementos centrales y abrirse hacia la periferia; y la elaboración de subsistemas (proporciona a cada unidad núcleos y periferia antes de continuar con la siguiente), que va dotando una secuencia de unidades representativas con ligaduras semánticas y geométricas. El segundo muestra cómo un objeto es representado en un sistema conceptual, como abstracción de rasgos centrales de los objetos de una categoría, en una posición canónica, organizada según "peso" o "relieve".

Para Picard y Vinter (2005), estos patrones se distinguen según el desarrollo cronológico, sobre todo en cuanto a la introducción de elementos novedosos. Las diferencias entre tareas libres o sobre un modelo se refieren a la extensión de la categoría en función de sus elementos periféricos y no de los nucleares, siendo mayor su extensión cuando se presenta un modelo, incrementándose según la edad. La organización conceptual de rasgos de un objeto y sus pesos semánticos determina su secuenciación en las fórmulas gráficas; la categoría conceptual y su fórmula gráfica se desarrollan conjuntamente. La plasticidad se afecta por influencias en conflicto entre dos principios del ordenamiento, el semántico y el geométrico (perceptivo). La fuerza semántica se encarga del orden de los rasgos según su peso semántico; la fuerza geométrica y perceptiva, del orden en la producción de atributos en su proximidad espacial. La fórmula gráfica representaría un objeto en relación con su categoría en el sistema conceptual infantil.

De la misma forma, la mediación cultural en el desarrollo simbólico del dibujo, según Callaghan y Rankin (2002), promueve la adquisición de sistemas simbólicos en la infancia, algunos de cierta complejidad, como el lenguaje, y otros dependientes de la necesidad cultural atribuida al enclave en particular, como la matemática o los grafismos, difiriendo en su complejidad y su significado en las diferentes culturas, en concordancia con modalidades del espacio simbólico. Su pregunta es si durante la infancia se requiere una comprensión en ciernes de la relación simbólica para que la mediación cultural surta su efecto o una mayor exposición al simbolismo durante la infancia, así como situar el surgimiento del simbolismo gráfico en el marco general del desarrollo simbólico. El surgimiento del simbolismo gráfico, así como del juego simbólico, aparecen hacia los tres años, posteriores al precoz desarrollo del lenguaje (luego del primer año); juego y lenguaje tienen una estructura jerárquica que inicia con gestos pre-simbólicos en los cuales significado y acción se funden (el gesto de beber y la taza vacía), para luego desarrollar un simbolismo descentrado (independiente de acciones sensorio-motoras con palabras abstractas) y culmina con la combinación de acciones lúdicas y palabras. Al adherirse al desarrollo del lenguaje, la aparición de una única función simbólica 
diferida tiene sus predecesores en la comprensión previa y facilita la producción pictográfica, culminante a los tres años. Esta divergencia en un proceso guiado por el mismo principio sería determinada por mediación cultural y prioridades de estimulación en cada sistema, para lo cual es necesario el estudio de tres dominios (grafismo, juego y lenguaje), controlando el apoyo a cada uno por diferentes agentes sociales y la jerarquía de inversión en cada uno de los sistemas simbólicos en la cultura, por la fuerte mediación del lenguaje desde el nacimiento y la más moderada del juego hacia el segundo año.

Callaghan y Rankin (2002) también preguntan: 1. ¿puede la mediación social de una instancia simbólica sobre dibujos acelerar el surgimiento de la comprensión simbólica en el grafismo?, 2. ¿el entrenamiento es más efectivo si es temprano y extensivo o breve y tardío?, 3. ¿existen relaciones internas en la comprensión simbólica entre grafismo, juego y dominios lingüísticos? Respecto a la primera pregunta, encuentran que la participación de adultos acelera el surgimiento tanto de la producción como de la comprensión del simbolismo gráfico; respecto a la segunda, el entrenamiento resultó más efectivo cuando se aplica tempranamente, aunque sus resultados se evidencian luego de algún tiempo y deba darse con mayor frecuencia en relación inversa con la edad. Debido al temprano privilegio del lenguaje, el infante entiende la naturaleza simbólica del grafismo y el juego cuando opera fuera de aquel dominio y no recurre a él como filtro. Su respuesta a la tercera pregunta es que un patrón general de dominio guía al desarrollo del funcionamiento simbólico; la diferencia de desarrollo y los logros en cada esfera dificultan la aseveración de la interacción entre ellos, sobre todo por diferencias en la inducción cultural en cada uno y la influencia del sistema simbólico del lenguaje en el juego y el grafismo, ya que la participación del lenguaje resalta un efecto sobre los otros dos, pero su supresión no establece la determinación que juegan estos últimos, lo cual remite a la interrogante sobre la influencia cultural y la dominancia lingüística que podría variar por contextos y énfasis simbólicos. La relación simbólica del contexto cultural por medio del lenguaje se extiende a otros dominios gracias a la invitación cultural y las prioridades del mundo adulto.

Por su parte, Calaghan y Rochat (2003) establecen, a los cuatro años, habilidades para razonar sobre atributos de la simbología visual (sentido procurado y emociones participantes) como intencionalidad, creencias y vivencia del autor. Al considerar "la mente detrás del símbolo", distinguen que el estado de ánimo puede o no estar involucrado (parte del state of mind).

El análisis del estilo, agregan Pufall y Pesonen (2000), contempla qué es lo dibujado y cómo se dibuja, no solo en términos de técnicas empleadas o dominio de ciertos medios, sino en relación con experiencias, personalidad y competencias psico-motoras, recursos para enfrentar diferentes circunstancias cotidianas. Los mundos artísticos, fuente de placer, reflexionan sobre temas y expresividad artística, exploración que define su individualización. Se dibuja a partir de temas explorados y aspectos conceptuales interesantes, desde dispositivos artísticos requeridos; este proceso es distintivo de la modalidad de 
representación con aquello a comunicar. El estilo se compone de propiedades formales y temáticas. El estudio longitudinal de Pufall y Pesonen (2000), con técnicas prospectivas y retrospectivas para identificar dibujos infantiles entre los 5 y los 10 años, por medio de jueces y con motivos permanentes (hormiga, gato y murciélago), establece que no son posibles patrones que anticipen su desarrollo. Estilo y habilidad son independientes, varíen o no las temáticas, pues la principal destreza es comunicar el tema, representar una narración de manera pictórica, con escaso o del todo sin uso de palabras, en un contexto cultural. El mundo artístico depende de su lugar en la vida social junto a figuras adultas.

Finalmente, los mundos artísticos infantiles (Children's Artworlds) son analizados por Pufall y Pesonen (2000) como organizaciones o mundos sociales cooperativos, generatrices y propiciadores de obras artísticas en una elaboración mutua entre figuras adultas e infantiles. Su aparición es espontánea y en diferentes contextos domésticos o escolares, como parte de la instrucción o por diversión. Niños y niñas participan en estas iniciativas de distintas formas y les otorgan propósitos diversos, empezando con el ejercicio para el dominio de los medios y progresando hacia la identificación de temas y narraciones. El estilo posee significación psicológica sobre qué y cómo se dibuja. Niños y niñas dibujan para revivir, controlar y comprender sus experiencias y menos con el propósito de lograr imágenes bien diseñadas, son parte de sus experiencias subjetivas de placer, excitación e incluso dolor en relación directa con contenidos objetivos.

Este mundo artístico estaría, según la investigación de Ehrlén (2009), compuesto por las concepciones que la infantil dibujante tiene de su entorno y de sus mundos de vida. De esta manera, en el dibujo el o la delineante vierte experiencias del sí mismo junto a otros, recurriendo a diferentes niveles de representación, al contexto y a la calidad de las relaciones y el sentido otorgado a las acciones, elementos que conforman su comprensión escénica de los eventos que subyacen a la subjetivación. El dinamismo del dibujo descrito en esta parte se muestra como cosecha de las múltiples dimensiones en que el niño y la niña están realizando su participación como sujetos sociales y derivando las claves de la convivencia. Los procesos de apropiación subjetiva aquí descritos ejemplifican el principio planteado por Lorenzer (1986) sobre el juego interactivo que se ilustra en la manipulación de objetos, en la cual la articulación de los significados culturales es primordial.

Ningún dibujo es un trazo azaroso, cada uno es una forma de comunicación de la experiencia tal y como es asimilada por el sujeto. La clave para descifrarlo no está en su complejidad, sino en el sentido que le imprime el dibujante. 


\section{Dibujos y escenas}

El carácter escénico del dibujo infantil, a partir de la consigna de representar una familia haciendo algo, se muestra en la naturaleza cotidiana de los motivos, así como en los artilugios para el efecto dinámico en la situación seleccionada. Los dibujos analizados a continuación fueron realizados por niños y niñas de primer grado, de una comunidad rural, con un promedio de edad de 7.3 años (D.S. 6.9 - 7.8), en el marco de una investigación sobre detección temprana del abuso sexual y sus factores de riesgo (Sanabria, 1994). Los dibujos deberían permitir la identificación de algunos rasgos sobresalientes del proceso de representación de niños y niñas, con el propósito de elucidar su capacidad de representación y expresividad sobre temas cotidianos y así, eventualmente, poder relacionarla con la forma en que se habían referido al tema en cuestión, lo cual debería proporcionar - como en efecto lo hizo - un parámetro de fiabilidad a los restantes instrumentos empleados. Para este artículo, han sido analizados independientemente de los propósitos de la investigación referida, para fines eminentemente de teorización sobre la producción pictográfica infantil.

Previo consentimiento informado de sus familias, a cada niño y niña se le expuso en un juego de simulación el propósito del estudio para verificar su disponibilidad a participar. La consigna consistió en realizar el dibujo de una familia "haciendo algo, cualquier cosa". Se recolectaron y clasificaron 168 dibujos de familia. El sistema de clasificación, diseñado por el autor, se sometió al criterio de dos expertos sobre factores de desarrollo y riesgo en la niñez y ha sido discutido, para su validación, en seminarios sobre Teoría del Apego y Socialización en la Escuela de Psicología de la Universidad de Costa Rica (2000 -2008), para su asignación definitiva. Los criterios para los patrones escénicos fueron:

Espacio: desplazamiento en planos horizontal - vertical y cantidad requerida.

Escenografía: excluidos los miembros de la familia (en cualquier composición), elementos como flora, fauna, geografía, arquitectura, animales domésticos, enseres, vehículos o herramientas, en combinaciones y cantidades variantes.

Actividad: nula o estática; presencia o ausencia de movimiento con dinamismo; colectiva diversa (actividad única en contexto común, pero con tareas distintas); diversa colectiva (personajes o grupos de personajes en diferentes papeles); colectiva no diversa (actividad única en contexto común que involucra a todos los personajes).

Estos elementos permiten, a su vez, variabilidad de combinaciones, en 18 de las cuales los dibujos fueron clasificados, para determinar destreza y recursos de representación. Finalmente, se agruparon en tres categorías que destacan la naturaleza escénica de los "mundos artísticos infantiles": contexto de familia, contexto laboral y contexto lúdico. Cada categoría es una combinación singular 
de elementos para lograr el efecto deseado: recrear cotidianidades, de una manera estética (poetizada).

\section{Dibujos en contexto de familia}

Al solicitarles el dibujo de una familia, niños y niñas producen una diversidad de motivos. Cuando se circunscriben a las figuras que componen la familia (Dibujo 1), destacan tres aspectos: proporción entre las figuras adultas e infantiles, distinciones de género y colocación de las figuras entre sí, lo cual insinúa las modalidades básicas de organización registradas. Estos factores se combinan en una composición que reproduce el entendimiento del sistema familiar.

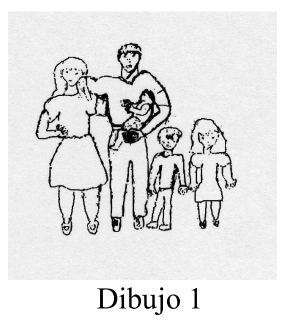

El grado de habilidad psico-motora y de destreza en el trazo, muestra diferentes niveles posibles de elaboración (Dibujo 1 en contraste con Dibujo 2). Desde el punto de vista de la representación, los elementos para estas composiciones y lograr el efecto deseado, aparecen de una manera frecuente.
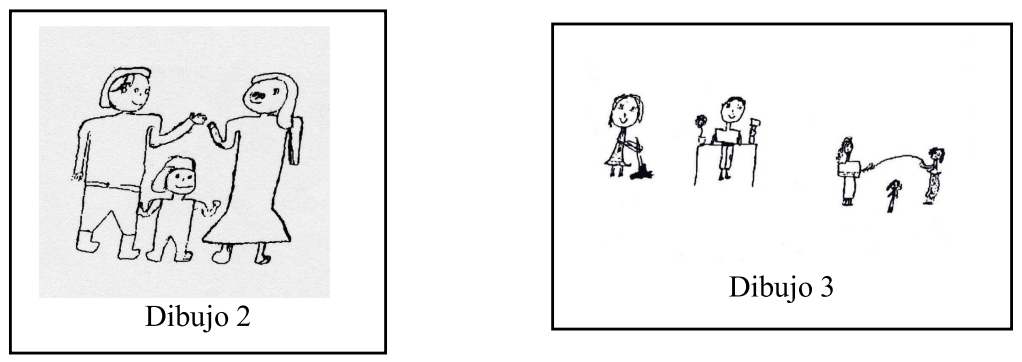

Objetos de la cotidianidad doméstica contribuyen a las situaciones o ambientes de la escena (Dibujo 3). Muestran, con pocos componentes, una semblanza más completa y dinámica, sin importar el nivel de elaboración.

En esta concepción, deben procurarse los primeros esbozos de la dimensionalidad, para avanzar hacia la perspectiva del espacio, doméstico o de cualquier otra índole. La tercera dimensión (Dibujo 4) es necesidad y recurso, cuando se expresa la sensación de profundidad y de combinación de momentos. El resultado no tiene que ser perfecto para lograr la ilusión, que se puede complementar con planos yuxtapuestos y transparencias (Dibujo 4 
versus Dibujo 5). Se puntualiza el ángulo distintivo del observador y del dibujante.
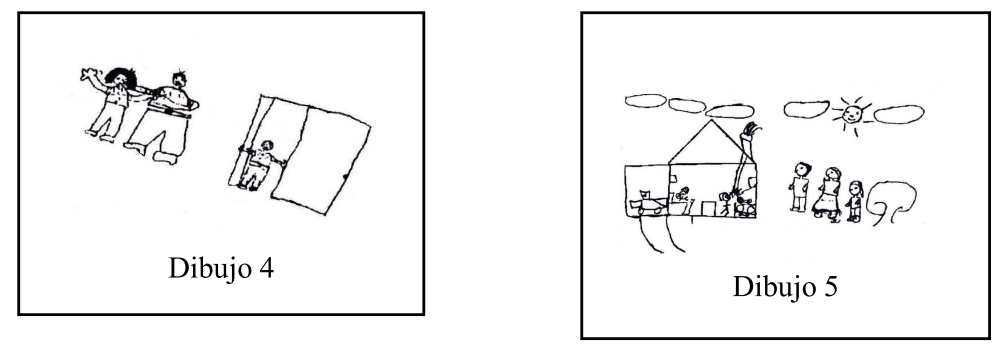

La diferenciación entre el espacio dentro y fuera de la casa de habitación (con alusión a elementos principales, como en los dibujos 4 y 5), significa una producción más compleja en cuanto a la pluralidad del significado. Pocos elementos consiguen planos espaciales (dibujo 4) o el intercambio interiorexterior, proponentes de actividades distintas, identificación de roles, tareas, juegos, diferentes lugares, para lo cual la "transparencia" permite el contraste (dibujo 5).

Las dimensiones que alimentan y se alimentan de la diferenciación de espacios para caracterizar situaciones, muestran, más decididamente, el intercambio entre el mundo familiar y el mundo social (dibujos 3 y 5). Objetos y ornamentos ambientales no solo son un lujo estético, sino referentes necesarios para recrear la situación sobre los elementos del exterior (casa, actividades, etcétera).

La caracterización de ambientes sociales, su contraste y mutua influencia están conceptuados en la infantil representación, para así lograr el efecto de encadenamiento de eventos que ofrece, al mismo tiempo, una continuidaddiscontinuidad de contextos. Al comparar el dibujo 6, con los elementos básicos pero claves, para lograr el efecto de "género y generaciones", pero todavía flotando en el espacio, y se compara con el dibujo 7, en el cual la caracterización de un momento cotidiano en el espacio doméstico muestra un refinamiento que recurre a la presencia de objetos, su utilización habitual y al intento de tercera dimensión, se pone de relieve el proceso de construcción de ambientes, sin perder el sentido inicial de representar una familia. La mayor destreza no necesariamente conlleva al aporte de algo nuevo (contraste entre dibujos 7 y 8), en cuanto al significado.

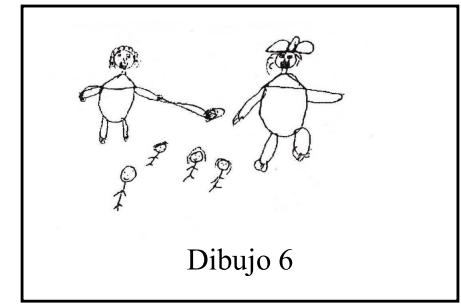

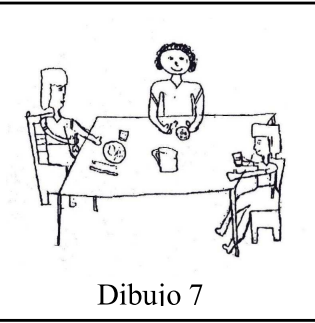




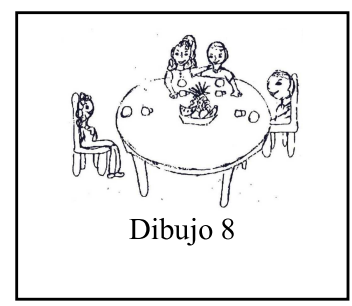

Es muy posible que estas opciones se abran a la creatividad de niños y niñas, para expresar el valor emocional y afectivo que las diferentes situaciones posibles adquieren dentro de la vida cotidiana, pues la sutileza de algunos trazos, para expresar texturas sociales, posturas, gestos o actividades, es tal que con poco esfuerzo se obtiene la referencia a la especificidad o la experiencia asociada al evento. Este recurso expresivo se asocia con la necesidad de mostrar aspectos sobresalientes y distintivos del sistema familiar y de ciertas coordenadas que rigen el mundo familiar y extra familiar (dibujo 9, los mellizos, o 10, un crucifijo, como elementos dominantes), que subraya un aspecto supra-cotidiano.
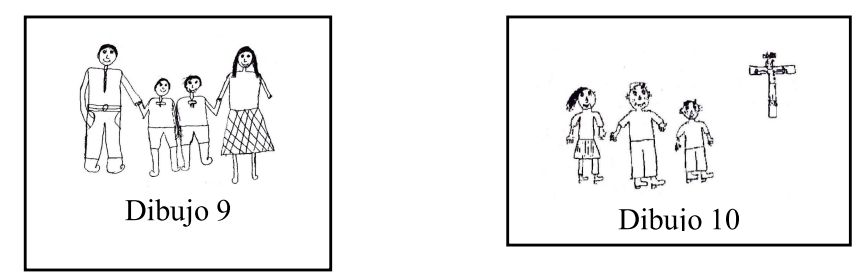

Aunque el dibujo sea sencillo e incluso primitivo en la representación de las figuras, elementos seleccionados organizan la ambientación y destacan una atmósfera (dibujos 11 y 12), en la cual papel y participación de la figura infantil logran un lugar singular y delineado sin ambigüedades.
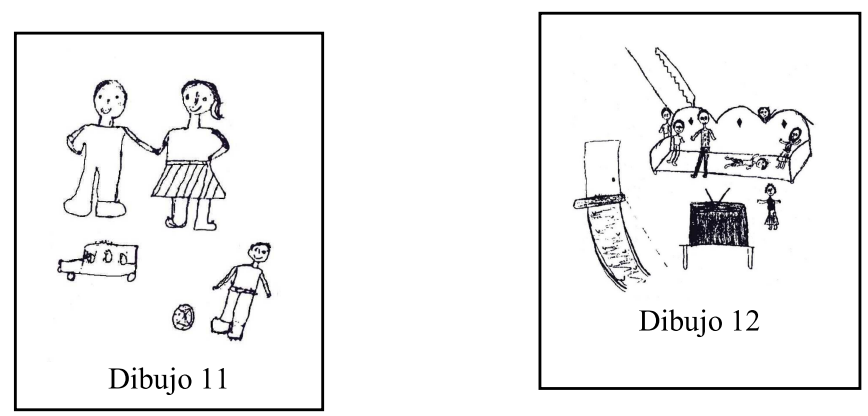

Los dibujos ponen de relieve la organización cotidiana al servicio de intereses infantiles, combinando intentos de tridimensionalidad con ambientaciones domésticas y la experiencia de momentos significativos. La combinación de los recursos señalados puede lograr una exuberancia que entrelaza las diferentes experiencias vistas como conjunto y concatenación de 
actividades y ambientes, en cada uno de cuyos componentes destacan rasgos que pueden transmitir el significado en la unidad de la composición (Dibujo 13).

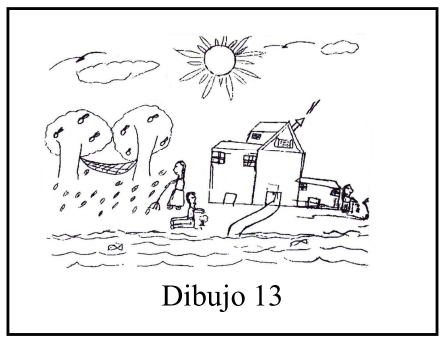

\section{Dibujos en contexto laboral}

La capacidad para percatarse de coordenadas de diferentes ámbitos del mundo social del cual participan, permite a niños y niñas reflejar su percepción por medio de la asignación de funciones, tareas, hábitos y costumbres. El trabajo es una actividad de relevancia en las interacciones que decantan. Insinuación de utensilios y movimientos construyen la referencia a los contextos evocados (dibujos 14 y 15).
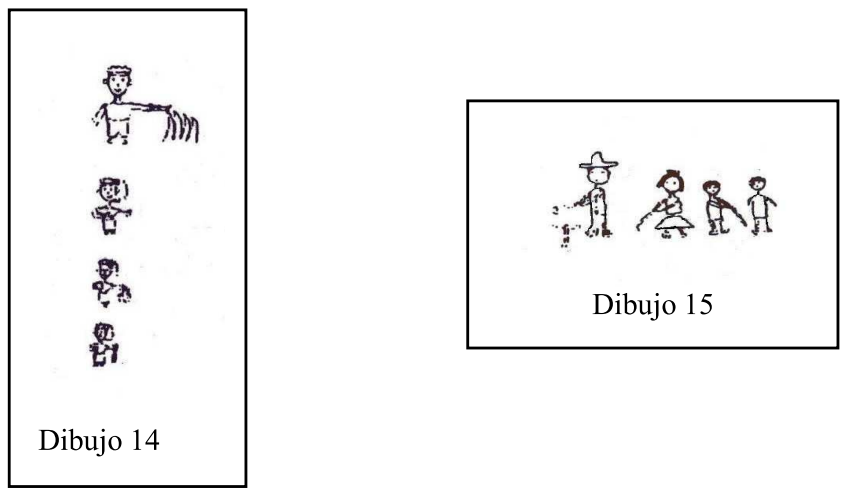

Por tratarse de niños y niñas de una zona rural, la mayoría de las actividades laborales plasmadas están relacionadas con el agro, prueba de que el involucramiento subjetivo y la derivación de principios fundamentales de la organización se captan como eventos complejos en una representación dinámica. Por supuesto, el trabajo doméstico es parte de esta dimensión y, como tal, amerita una cualificación en las imágenes con que niños y niñas se manejan (dibujo 16).

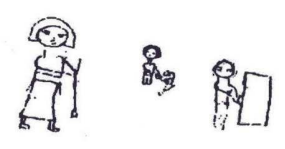

Dibujo 16 
Este efecto puede lograrse con trazos básicos y delineamientos delicados, que apenas rozan la superficie o contornos de las siluetas, pero que, al decantar lo esencial, muestran su intención (dibujo 17). Asimismo, ornamentos y algo más de destreza aportan al dibujo dinamismo, pero no mayor cualificación simbólica de lo esencial (dibujo 18).

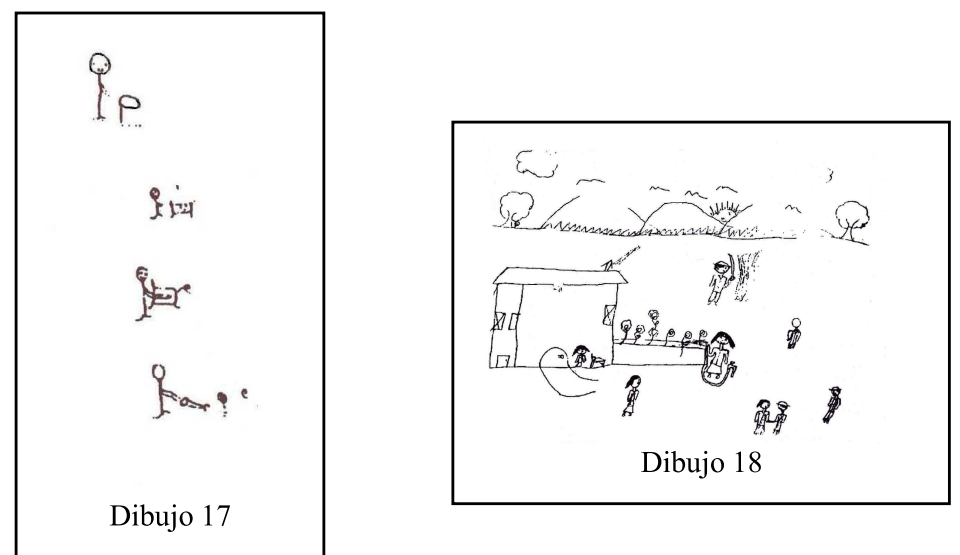

Dos o tres elementos exteriores son suficientes para caracterizar el contexto y conseguir el impacto visual de la labranza o el cultivo. Se presentan incluso como conjuntos de situaciones, como la integración de tareas simultáneas y relacionadas de distintas maneras, dentro y fuera del hogar, cuando se cumplen labores compartidas en un espacio común, en el que se presentan actividades diferentes. Eventos simultáneos, interdependientes, armoniosos y cada uno con una cualidad diferente, según parámetros de espacio, tiempo, género y edad, logran, con dimensionalidad, diversidad y manejo simultáneo de interior-exterior, variabilidad en formas y movimientos (Dibujo 18).

\section{Dibujos en contexto lúdico}

El juego, a la edad de las niñas y los niños dibujantes de estas obras, es una actividad axial, colectiva, con reglas y organizaciones no siempre simples, pues implican acuerdos, pautas y cooperación recíproca. La diversión depende del consenso en que descansa. Estos aspectos pueden dibujarse con rasgos simples, elecciones tácticas y características esenciales (dibujo 19).

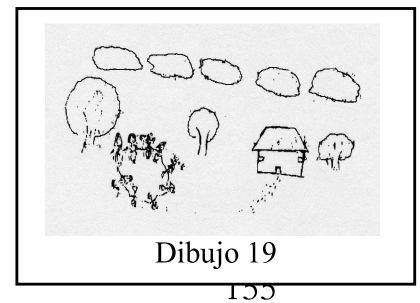


La mayor elaboración juega con perspectivas y espacios, con detalles que diferencian el papel adulto y la naturaleza lúdica de las actividades infantiles, así como el lugar que corresponde a cada quien (Dibujos 20 y 21).
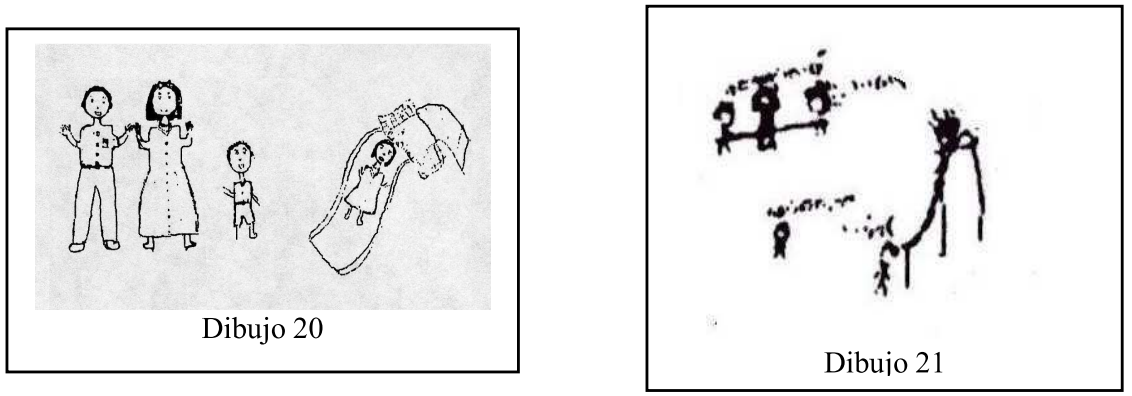

En tanto actividad colectiva en la infancia, la composición puede mostrar el esparcimiento como dimensión infantil inscrita en el juego que se comparte en familia o con los pares y que se lleva a cabo en contextos particulares como un acercamiento al dominio público y participar de actividades ofrecidas socialmente. Para captar estas cualidades no requieren destrezas o técnicas de alto nivel, con tal de que los elementos seleccionados rescaten vectores de la situación y su movilidad (dibujo 22).

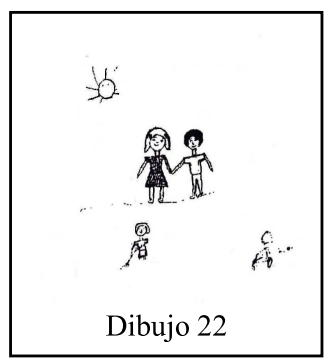

Pequeñas variaciones crean situaciones diferentes, con sentido distinto y referencia a actividades de diversa índole, como la recreación familiar que remite a otros contextos y momentos de la vida familiar (dibujo 23 y 24), con el juego otorgándole el significado principal a la escena.
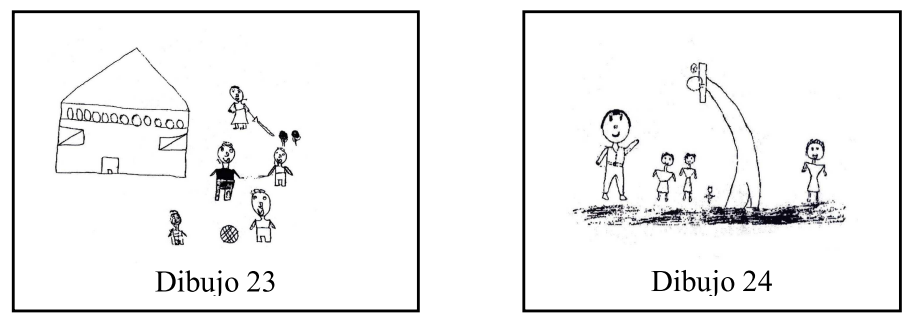
El juego es, por su naturaleza, a esta edad, colectiva y participativa, proyección del sí mismo en la sociabilidad y participación en actividades extra familiares, con acuerdos que aunque se sustenten en la socialización familiar, requieren revisión en los nuevos ámbitos (dibujo 24), para lo cual un solo elemento puede erigir toda la situación.

Mundo familiar y mundo social (extra familiar), convergen y se traslapan, aspecto que se puede calificar con un manejo sencillo del espacio, con la simultaneidad de ambientes, eventos y espacios (Dibujo 25), a los cuales se pone a disposición la tentativa de dimensionalidad.

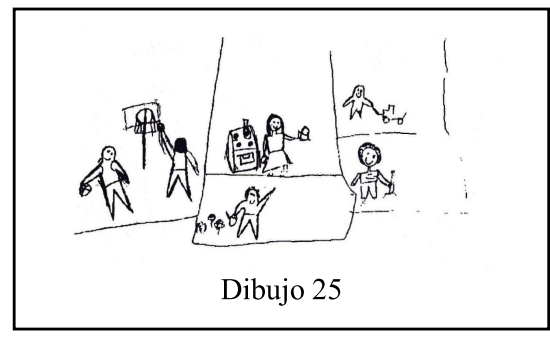

Aunque ya pueda haber quedado claro que estos dibujos son composiciones poetizadas por niños y niñas sobre sus experiencias cotidianas, no es ocioso mostrar cómo pueden recoger anhelos o deseos, rescatados en una escenografía imaginaria que aspira a vivencias quizá aún no accesibles o por realizar, como un paseo con equipo de película (dibujo 26), puesto que los objetos tienen un significado que no está ligado siempre de una manera directa a su uso práctico-instrumental, sino que cobran sentido por sí mismos en la medida en que denotan estados de ánimo o situaciones en su conjunto.

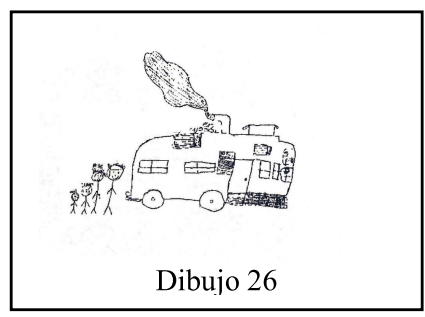

\section{El carácter escénico, en breve}

Es posible derivar, al menos, las siguientes pautas sobre el dibujo infantil:

a) Partícipe del desarrollo cognitivo, social y emocional, entreteje habilidades psicomotoras, juego, lenguaje, influencia cultural y representación simbólica. 
b) Más que su evolución cronológica, importan los componentes comprometidos en su producción en una etapa del desarrollo infantil (microgénesis).

c) Su función comunicativa, desde etapas pre-verbales, llega a involucrar al lenguaje.

d) Enlaza diferentes niveles interactivos (individuo-individuo, individuoentorno), no conscientes, pero a ser apropiados en habilidades, destrezas y creatividad (estilos).

e) Refleja el mundo infantil, la capacidad para comprender, apropiarse y mostrar la visión del entorno social de inscripción subjetiva en mundos artísticos y mundos infantiles.

f) El valor simbólico (semántico) es central para interpretar la representación particular.

g) Expresa dimensiones de la subjetivación de la identidad cultural y de género.

h) Refleja relaciones sociales integradas a la biografía interna y figuras de la vivencia (figuras de la praxis), escenas o bosquejos de vida cotidiana.

i) Sus figuras en contextos (movimiento, acción o ilustración de situaciones paradigmáticas o únicas), se rigen por la representación escénica (figuras en interacción en contextos de interacción) y son analizables por medio de la comprensión escénica (una hermenéutica profunda de la génesis de la creatividad).

$\mathrm{El}$ análisis compromete forma y contenido (cómo y qué se dibuja) y el relato asociado al dibujo y la consigna. Implica la irrenunciable participación de la dibujante (desde su relato sobre el dibujo, las emociones asociadas, la intencionalidad y sentido de los trazos o rasgos, el estilo y mundo artístico infantil subyacente, etcétera).

Por tanto, la infantil dibujante parte de una comprensión escénica (una escena para un espectador, aunque lo sea, y en muchos casos lo será, el espectador interno), nutrida cognitiva, emocional y culturalmente por medio de interacciones cotidianas, para llegar a una representación escénica que, para su dilucidación, depende, a su vez, de una interpretación interactiva con participación de dibujante, relato y analista.

\section{Discusión}

La exposición precedente permite formular algunas afirmaciones básicas sobre el proceso de generación de una obra iconográfica por medio del dibujo infantil. La premisa fundamental es que la producción puede abordarse como la desagregación de tres factores. El primero es la apropiación de un esquema corporal, de su funcionamiento y las habilidades a que faculta, como experiencia de vida, lo que equivale a decir, de una experiencia con y junto a otros. A esta apropiación subyace un fundamento psico-fisiológico que se 
evidencia en las habilidades sensorio-motoras requeridas. Se ha expuesto, entonces, cómo estas habilidades, en progreso y diversificándose con no poca ayuda de la obra pictórica por sí misma, se ponen al servicio de las necesidades expresivas y de representación de la vivencia en el infantil sujeto. El segundo factor es que al dibujar, niños y niñas derivan en el pictograma rasgos sobresalientes y significativos de su entorno vivencial, tal y como les es presentado y como lo han experimentado.

El dibujo infantil recoge eventos cargados de significado, bajo la impronta de la subjetividad emergente, ya sea como elaboración espontánea o guiada por instrucciones adultas, puesto que en ambos casos se trata de situaciones reales o imaginadas en las que se involucran interacciones entre el mundo infantil y el mundo adulto (Sanabria, 2007). Niños y niñas, al dibujar, parten de una "consigna", ya sea deliberadamente ofrecida por figuras adultas (o sus propios pares) o impuesta desde los marcos referenciales que han incorporado, lo cual equivale a decir que se derivan de una interacción ya sea concreta o reproducida desde los modelos simbólicos incorporados vía socialización. Este aspecto pone de relieve que el dibujo es parte de un complejo de estructuras mucho mayor, que incluye al juego simbólico y que preceden al advenimiento del lenguaje, en el que todas han de culminar.

El tercer componente resalta la capacidad simbólica de convocar en un conjunto los elementos y rasgos distintivos para la identificación de las situaciones expresadas en el dibujo. La dimensión simbólica, de carácter presentativo, pone de relieve los mecanismos de representación que se articulan desde la base neuronal hasta el producto representacional en el dibujo. Son representaciones simbólicas, con respaldo en un esquema corporal (desde la base neuronal en la que se inscriben las cogniciones y las emociones), dotadoras de habilidades específicas que facultan a la infantil dibujante su capacidad expresiva, la cual se pone de manifiesto en el diálogo que es posible desprender a partir del contenido dibujado.

Es posible también derivar el carácter escénico del dibujo del trabajo presentado por Chen (2003), por medio del cual niños y niñas son capaces de resolver problemas por analogía, al utilizar como guía la información conceptual provista por el dibujo de situaciones paradigmáticas y transferirla a situaciones del mundo social, lo cual implica una decodificación del significado y una reelaboración por ser aplicada a los dilemas asociados a los eventos que se presentan. Asimismo, Moriarty (2009) ha recurrido a dibujos infantiles, y a las narraciones a ellos asociadas, para investigar el concepto de espiritualidad y la simbología que se le atribuye, así como el uso de la imaginación, utilizando una visión del conjunto formado por el pictograma y la narrativa que facilita, sobre todo en la relación con figuras adultas, gracias al ejercicio de interpretación compartida de la obra desde el enfoque de un lenguaje metafórico que genera significados.

Que el dibujo solo sea comprensible por el conjunto de la situación que procura mostrar y que el relato asociado sea revelador de buena parte de las intenciones de representación de la dibujante, muestra su carácter escénico; la 
escena solo es accesible a la comprensión como escena interactiva, con y junto a otros, reales o imaginados, en contextos de vida y desde mundos simbólicos durante el proceso de inscripción cultural del sujeto. Entonces, la comprensión escénica, tal y como es propuesta por Lorenzer (1986; cf. Sanabria, 2007), como interpretación del nexo que propone una obra plástica con su interlocutor (como algo vivido que puede ser compartido, según la expresión de MacDonald, 2009), aun en este caso, el espectador del dibujo infantil, no solo permite la dilucidación del contenido del dibujo, por medio de la apelación al propio historial de socialización del intérprete y su conexión con la intencionalidad de la infantil dibujante, cerrando así un círculo hermenéutico, sino que, además, pone de relieve los diferentes niveles de la subjetivación involucrados en la producción iconográfica: red neuronal, habilidades psicomotoras y simbolización. Como se ha visto, estos niveles permiten diferentes combinaciones, según la escena a representar.

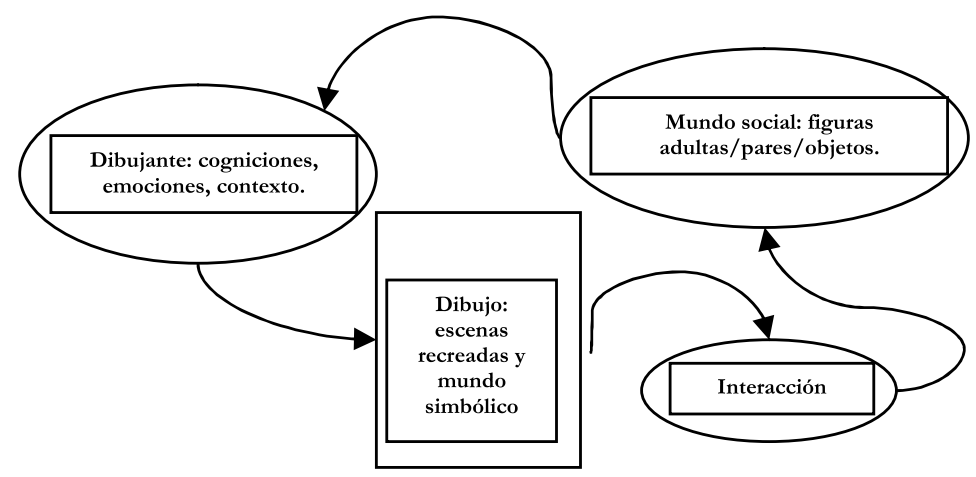

Figura 1. Proceso de representación pictográfica

\section{Referencias}

Boyatzis, C. (2000). The artistic evolution of mommy: a longitudinal case study of symbolic and social processes. New directions for child and adolescent development, 90, 5-29.

Boyatzis, Ch. y Albertini, G. (winter 2000). A naturalistic observation of children drawing: peer colaboration processes and influences in children's art. New directions for child and adolescent development, 90, 31-98.

Braswell, G. y Rosengren, K. (2000). Decreaseing variability in the development of graphic production. International Journal of Behavioral Development, 24(2), 153-166.

Braswell, G. y Rosengren, K. (2005). Children and mothers drawing together: encountering graphic conventions during social interactions. British Journal of Developmental Psychology, 23, 299-315.

Burkitt, E., Barret, M. y Davis, A. (2003a). The effect of affective characterizations on the use of size in children's drawings. British Journal of Developmental Psychology, 21, 565-584.

Burkitt, E., Barret, M. y Davis, A. (2003b). Children's colour choices for completing drawings of affectively characterized topics. Journal of child psychology and psychiatry, 44, 445-455.

Burkitt, E., Barret, M. y Davis, A. (2004). The effect of affective characterizations on the use of size and colour in drawings produced by children in the absence of a model. Journal of Educational Psychology, 24 (3), $315-343$. 


\section{Dibujo infantil y comprensión escénica: análisis crítico hermenéutico desde un enfoque psicoanalítico}

Callaghan, T. y Rankin, M. (2002). Emergence of graphic symbol functioning and the question of domain specifity: A longitudinal training study. Child Development, 73, 2, 359-376.

Callaghan, T. y Rochat, P. (2003). Traces of the artist: sensitivity to the role of the artist in children's pictorial reasoning. British Journal of Developmental Psychology, 21, 415-445.

Carlson, E., Sroufe, A. y Egeland, B. (2004). The construction of experience: A longitudinal study of representation and behavior. Child Development, 75, 1, 66-83.

Chen, Z. (2003). Worth. One thousand words: Children's use of pictures in analogical Problem Solving. Journal of Cognition and Development, 4(4), 415-434.

Cherney, I. D., Seiwert, C. S., Dickey, T. M. y Flichtbeil, J.D. (2006). Children's drawings: A mirror to their minds. Educational Psychology. 26, 1, 127-142.

Cox, M. y Mason, S. (1998). The young child's pictural representation of the human figure. International Journal of Early years education, 6, 1, 31-38.

Cox, M. y Wright, R. (2000). Relative heights of males and females in children's drawings. International journal of early years education, 8, 31, 217-226.

Cox, S. (2005). Intention and meaning in young children's drawing. International Journey of Art and Design Education, 24,2, 115-125.

Cugmas, Z. (2004). Representations of the child's social behavior and attachment to the kindergarten teacher in their drawing. Early Child Development and Care, 174, 1, 13-30.

Einarsdottir, J., Dockett, S. y Perry, B. (2009). Making meaning: Children's perspectives expressed through drawings. Early Child Development and Care, 179, 2, 217-232.

Ehrlén K. (2009) Drawings as representations of children's conceptions. International Journal of Science Education. 3, 1, 41-57.

Fury, G., Carlson, E. A. y Sroufe, L.A. (1997). Children's representation of attachment relationships in family drawings. Child Development, 68, 6, 1154-1164.

Jolley, R.P., Fenn, K. y Jones, L. (2004). The development of children's expressive drawing. British Journal of Developmental Psychology, 22, 545-567.

Karmiloff, K. y Karmiloff-Smitn, A. (2001). Pathways to language. From fetus to adolescent. Cambridge: Harvard University Press.

Laak, J., Goede, M. de, Rijswijk, P. van (2005). The draw a person test: an indicator of children's cognitive and socioemotional adaptation? The Jounal of Genetic Psychology, 166, 1, 77-93.

Leon, K., Wallace T. y Rudy D. (2007). Representations of parent-child alliances in Children's Family Drawings. Social Development, 16, 3, 440-459.

Lorenzer, A. (1986). Das Konzil der Buchbalter. Die Zertörung der Sinnlichkeit, eine Religionskritik. (The Council of the Acountants. The Destruction of Sensuousness. A critique of Religion). Alemania: Europäische Verlagsanstalt.

Lorenzer, A. (2002). Die Sprache, der Sinn, das Unbewusste. Psychoanalytisches Grundverständnis und Neurowissenchaften (Language, Sense and Unconscious. Psychoanalytical fundamental Comprehension and Neurosciences). Alemania: Klett-Cota.

Merry, R. y Robins, V. (2001). Triangle wheels and the ghost in a girl's skirt: young children's representation of unreality. Early years, 21, 1, 41-53.

MacDonald, A. (2009). Drawing stories: The power of children's drawings to communicate the lived experience of starting school. Australian Journal of Early Childhood, 34, 2, 40-49.

Moriarty, M. W. (2009). Evaluating children's use of symbol in some recent research. International Journal of Children's Spirituality, 14, No. 1, 47-61.

Morra, S. (2005). Cognitive aspects of change in drawings: a neo- piagetian theoretical account. British Journal of Developmental Psychology, 23, 317-341.

Panagiotaki, G., Nobes, G. y Banerjee, R. (2006). Children's representations of the earth: A methodological comparison. British Journal of Developmental Psychology, 24, 353-372

Picard, D. y Vinter, A. (2005). Development of graphic formulas for the depiction of familiar objects. International Journal of Behavioral Development, 29, 5, 418-432.

Pufall, P. y Pesonen, T. (2000). Looking for the development of artistic style in children's art worlds. New directions in child and adolescent development, 90, $81-98$.

Ringenbach, S. D. y Amazeen, P. G. (2005). How do children control rate, amplitude, and coordination stability during bimanual circle drawing? Ecological Psychology, 17, 1, 1-18.

Sanabria, J. (1994) Indicadores de abuso sexual en población escolar de la Región Chorotega - Costa Rica Investigación para OPS. Manuscrito sin publicar.

Sanabria, J. (2000). Estudio sobre prevalencia del abuso sexual infantil en niños y niñas de edad escolar. Manuscrito sin publicar.

Sanabria, J. (2007). Hermenéutica profunda y análisis de la cultura. Masculinidad y feminidad en dos poemas de Pablo Neruda. Costa Rica: UCR. 
Sanabria, J. (2010). Mundo simbólico y mundo social infantil. Reflexiones, 89 (1), 45-65.

Sheppard, E., Ropar D. y Mitchell, P. (2005). The impact of meaning and dimensionality on the accuracy of children's copying. British Journal of Developmental Psychology, 23, 365-381.

Tenenbaum, H. R., Hill, D. B., Joseph, N. y Roche, E. (2010). 'It's a boy because he's painting a picture': Age differences in children's conventional and unconventional gender schemas. British Journal of Psychology, 101, 137-154.

Toomela. A. (2003). Developmental stages in children's drawings of a cube and a doll. Trames, 7, 57/52, 3 , $164-182$

Vinter, A. y Perruchet, P. (2000) Implicit learning in children is not related to age: evidence from drawing behavior. Child Development, 71. 5, 1223 - 1240.

Watson, M. W. y Schwartz, S. N. (winter 2000). The development of individual styles in children's drawings. New Directions for Child and Adolescent Development, 90, 49- 63.

Wu, L-Y. (2009). Children's graphical representations and emergent writing: evidence from children's drawings. Early Child Development and Care. 179, 1, 69-79.

Recibido: 20 de febrero de 2009

Aceptado: 1 de setiembre de 2010 